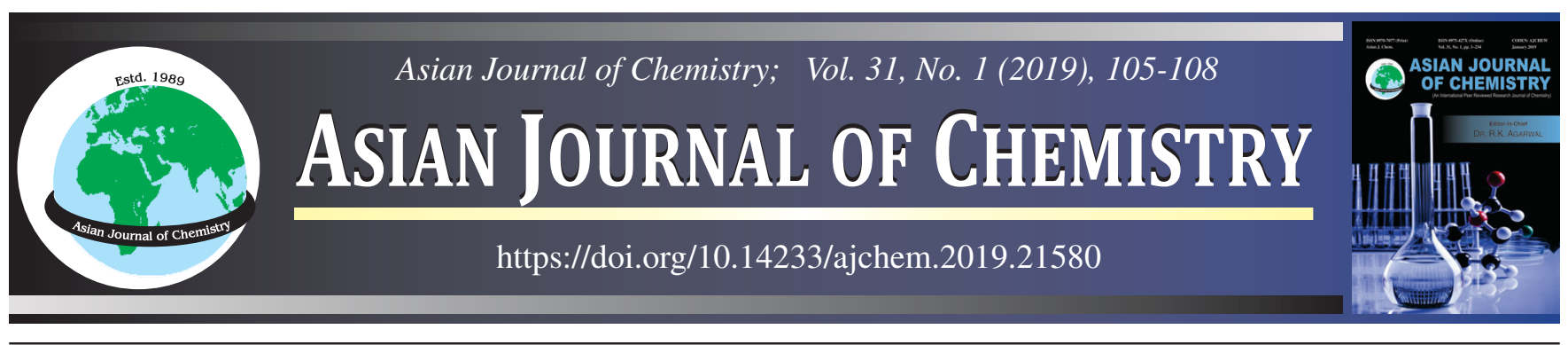

\title{
A New Synthetic Route for Preparation of Enantiomers of Gossypol and Apogossypol from Racemic Gossypol
}

\author{
Vu Dinh Tien, Vu Van Vu and Tran Khac Vu*
}

School of Chemical Engineering, Hanoi University of Science and Technology, No. 1 Dai Co Viet, Hai Ba Trung, Hanoi, Vietnam

*Corresponding author: E-mail: vu.trankhac@ hust.edu.vn

Received: 13 July 2018;

Accepted: 26 August 2018;

Published online: 30 November 2018;

AJC-19166

The paper described the preparation of enantiomers of gossypol and apogossypol from racemic gossypol via a two-step procedure. In the first step, D-tryptophan methyl ester was used as an effective agent to resolve racemic gossypol into (-)-gossypol and (+)-gossypol. Next,

the deformylation reaction of the corresponding (-)-gossypol and (+)-gossypol was conducted in sodium hydroxide solution, followed by | sulfuric acid neutralization in inert atmosphere and the resulting precipitate was filtered and washed with water to give (-)-apogossypol and (+)-apgossypol, respectively in high yields and in high enantiomeric excesses.

Keywords: Racemic, (-)-Gossypol, (+)-Gossypol, D-Tryptophan methyl ester, (-)-Apogossypol, (+)-Apogossypol.

ᄂ - - - - - - - - - - - - - - - - - - - - - - - - - - - -

\section{INTRODUCTION}

Gossypol (1) isolated from cotton seed has recently received the increasing attention because it possesses a wide range of biological activities, including anticancer [1-4], contraceptive [5], antiviral [6-8] or antimicrobial activities [9]. Due to hindered rotation about the 2,2'-binaphthyl bond, gossypol exhibits two optically active forms, $R$-or (-)-1 and $S$-or (+)-1. Research in both in vitro and in vivo showed that the (-)enantiomer is more potent than the $(+)$-enantiomer and the racemic mixture (1) [10]. It was also hypothesized the selective action at low doses of the (-)-gossypol and a nonselective action from higher doses of either enantiomer [10]. Regarding the mechanism of action, the (-)-gossypol targets Bcl-2, Bcl$\mathrm{xL}$ and Mcl-1 proteins with higher affinities than (+)-gossypol. It is now in clinical trials as an orally administered agent for the treatment of several types of human cancer [11]. However, the application of gossypol as a therapeutic agent was limited because of the presence of the aldehyde group in its structure, resulting a number of side effects [12].

Apogossypol (2) is a reduced product of gossypol (1). Preclinical in vivo data show that apogossypol (2) has superior efficacy and markedly reduced toxicity compared to gossypol (1) [13]. In addition, the evaluation of the single-dose pharma- cokinetic characteristics of compound $\mathbf{2}$ in mice indicated that compound 2 displays superior blood concentrations over time in comparison with compound $\mathbf{1}$ because it has slower clearance, indicating that compound 2 could be a promising lead compound for cancer therapy in the future [14]. Thus, significant attention has been focused on potential therapeutic value of apogossypol (2) and apogossypol derivatives as a promising starting point for the development of antitumor derivatives for medicinal applications with enhanced bioactivity and reduced side effects [15-18].

To understand the mechanism by which apogossypol exhibits its broad biological activities, the preparation of the enantiomer of gossypol and apogossypol in high chemical yield and enantiomeric purity is highly desirable.

So far, a number of methods for the preparation of optically active (-)-gossypol and (-)-apogossypol from racemic mixture have been studied and reported [19]. However, the reported methods lack its feasibility in practical preparation. As a result, the development of a practical method for the production of (-)-gossypol and (-)-apogossypol in large quantities is important from both application and scientific view points. Intrigued by this practice, this paper presents a simple and improved method for the preparation of (-)-gossypol and (-)-apogossypol from racemic gossypol.

This is an open access journal, and articles are distributed under the terms of the Creative Commons Attribution-NonCommercial 4.0 International (CC BY-NC 4.0) License, which allows others to copy and redistribute the material in any medium or format, remix, transform, and build upon the material, as long as appropriate credit is given and the new creations are licensed under the identical terms. 


\section{EXPERIMENTAL}

All products were examined by thin-layer chromatography (TLC), performed on Whatman 250lm Silica Gel GF Uniplates and visualized under UV light at $254 \mathrm{~nm}$. Melting points determined in open capillaries on Electrothermal IA 9200 Shimazu apparatus and uncorrected. Purification was done by crystallization. Optical rotations were recorded on Polarimeter P8000-T instrument as an average of six determinations. Nuclear magnetic resonance spectra $\left({ }^{1} \mathrm{H}\right.$ and ${ }^{13} \mathrm{C}$ NMR $)$ were recorded using tetramethylsilane (TMS) as an internal standard on a Bruker 500 $\mathrm{MHz}$ spectrometer with DMSO- $d_{6}$ and $\mathrm{CDCl}_{3}$ as solvents. Chemical shifts are reported in parts per million (ppm) downfield from TMS as internal standard and coupling constants $(J)$ are expressed in hertz $(\mathrm{Hz})$. All reaction were conducted under inert atmosphere. Reagents and solvents were purchased from Aldrich or Fluka Chemical Corp. (Milwaukee, WI, USA) or Merck unless noted otherwise. Solvents were distilled and dried before use.

Synthesis of gossypol adducts $(3,4)$ : A solution of Dtryptophan methyl ester hydrochloride $(9.824 \mathrm{~g}, 0.038 \mathrm{~mol})$ and $\mathrm{NaOH}(1.52 \mathrm{~g}, 0.038 \mathrm{~mol})$ in ethanol $(60 \mathrm{~mL})$ was stirred at $45{ }^{\circ} \mathrm{C}$ and the racemic gossypol $(9.85 \mathrm{~g}, 0.019 \mathrm{~mol})$ was added. The mixture was stirred for $2 \mathrm{~h}$. The reaction was monitored by TLC and then allowed to warm to room temperature. The resulting precipitate from reaction was then filtered, washed with cold ethanol and dried under reduced pressure to obtain compound $S g, R-(3)(8.28 \mathrm{~g}, 95 \%):\left\{[\alpha]_{\mathrm{D}}{ }^{20}=+222^{\circ}(\mathrm{c}\right.$ $\left.0.160, \mathrm{CHCl}_{3}\right\} .{ }^{1} \mathrm{H}$ NMR $\left(500 \mathrm{MHz}, \mathrm{DMSO}-d_{6}\right): \delta 13.47$ (t, $J$ $=8.0 \mathrm{~Hz}, 2 \mathrm{H},-\mathrm{NH}), 10.91(\mathrm{~s}, 2 \mathrm{H}$, indole, $\mathrm{NH}), 9.77(\mathrm{~d}, J=$ 12.0, 2H), 8.41 (s, 2H, indole), $7.76(\mathrm{br}, \mathrm{s}, 2 \mathrm{H},-\mathrm{OH}), 7.47$ (d, $J=7.5 \mathrm{~Hz}, 2 \mathrm{H}$, indole), $7.43(\mathrm{~s}, 2 \mathrm{H}), 7.31(\mathrm{~d}, J=8.0 \mathrm{~Hz}, 2 \mathrm{H})$, $7.13(\mathrm{~s}, 2 \mathrm{H}), 7.02(\mathrm{t}, J=7.5 \mathrm{~Hz}, 2 \mathrm{H}), 6.93(\mathrm{t}, J=7.5 \mathrm{~Hz}, 2 \mathrm{H})$, 4.79 (s, 2H,-OH), $4.45(\mathrm{~m}, 2 \mathrm{H}), 3.65(\mathrm{~s}, 6 \mathrm{H}), 3.65-3.76(\mathrm{~m}$, $2 \mathrm{H}), 3.59$ (dd, $J=14.5,3.6 \mathrm{~Hz}, 2 \mathrm{H}), 3.23(\mathrm{dd}, J=14.5,9.5$ $\mathrm{Hz}, 2 \mathrm{H}), 1.92(\mathrm{~s}, 6 \mathrm{H}), 1.43(\mathrm{~d}, J=6.5 \mathrm{~Hz}, 6 \mathrm{H}), 1.42(\mathrm{~d}, J=6.5$ $\mathrm{Hz}, 6 \mathrm{H}) .{ }^{13} \mathrm{C}$ NMR $\left(125 \mathrm{MHz}, \mathrm{DMSO}-d_{6}\right): \delta 172.64,170.84$, 161.6, 149.65, 147.0, 146.24, 136.06, 131.51, 127.14, 127.12, $126.92,124.22,121.09,120.22,118.56,118.06,116.67$, $115.60,111.45,107.76,103.82,61.98,52.52,30.72,28.88$, $20.31,20.25,20.16$.

The ethanol mother liquor was then concentrated to dryness. The residue was extracted with dichloromethane and water. The combined dichloromethane was concentrated under reduced pressure to obtain $R g, R-(4)(8.67 \mathrm{~g}, 99.4 \%):\left\{[\alpha]_{\mathrm{D}}{ }^{20}=-106^{\circ}\right.$ (c $\left.0.160, \mathrm{CHCl}_{3}\right\} .{ }^{1} \mathrm{H}$ NMR (500 MHz, DMSO- $d_{6}$ ): $\delta 13.46$ (br, s, 2H,-NH), 10.91(br, s, 2H, indole, NH), 9.66 (br, s, 2H, 2H), 8.41 (br, s, 2H, indole), 7.95 (s, 2H, $-\mathrm{OH}), 7.48(\mathrm{~J}=7.5$ $\mathrm{Hz}, 2 \mathrm{H}$, indole), 7.43 (br, s, 2H), 7.31 (d, $J=8.0 \mathrm{~Hz}, 2 \mathrm{H}), 7.15$ (s, 2H), $7.04(\mathrm{t}, J=7.5 \mathrm{~Hz}, 2 \mathrm{H}), 6.96(\mathrm{t}, J=7.5 \mathrm{~Hz}, 2 \mathrm{H}), 4.79$ (s, 2H,-OH), $4.45(\mathrm{~m}, 2 \mathrm{H}), 3.67(\mathrm{~s}, 6 \mathrm{H}), 3.65-3.76(\mathrm{~m}, 2 \mathrm{H})$, 3.59 (dd, $J=14.5,3.6 \mathrm{~Hz}, 2 \mathrm{H}), 3.23(\mathrm{dd}, J=14.5,9.5 \mathrm{~Hz}$, $2 \mathrm{H}), 1.92(\mathrm{~s}, 6 \mathrm{H}), 1.43(\mathrm{~d}, J=6.5 \mathrm{~Hz}, 6 \mathrm{H}), 1.42(\mathrm{~d}, J=6.5 \mathrm{~Hz}$, $6 \mathrm{H}) .{ }^{13} \mathrm{C}$ NMR (125 MHz, DMSO- $\left.d_{6}\right): \delta 174.5,170.8,162.3$, 149.7, 146.2, 136.1, 131.5, 128.9, 127.3, 126.9, 123.8, 121.0, $119.7,118.5,115.6,114.2,111.4,109.4,103.8,62.0,54.8$, $30.8,28.7,20.3,20.2,20.1$.

Synthesis of $S$-(+)-gossypol (5) and $R$-(-)-gossypol (6): Compound 3 (8.808g, $9.59 \mathrm{mmol})$ was dissolved in a mixture of acetic acid and ether $(4: 1)(50 \mathrm{~mL})$. The reaction mixture was kept at -5 to $0{ }^{\circ} \mathrm{C}$ under nitrogen atmosphere and concentrated hydrochloric acid $(1.5 \mathrm{~mL})$ was then dropped into for $10 \mathrm{~min}$. The reaction was then stirred at room temperature for 72 and monitored by TLC. After the completion of reaction, the resulting D-tryptophan methyl ester was filtered and washed by an amount of dichloromethane. The filtrate was concentrated to the dryness and was dissolved in an amount of $30 \mathrm{~mL}$ of mixture of dichloromethane and $n$-hexane (2:1) and was kept in fridge for crystallization. $S$-(+)-gossypol (5) was obtained by filtering and washing with cold acetone in $85.2 \%$ yield $(4.23 \mathrm{~g}) ; 94.4 \%$ ee by HPLC. $[\alpha]_{\mathrm{D}}{ }^{20}=+349(\mathrm{c}$ $0.160, \mathrm{MeOH}) .{ }^{1} \mathrm{H}$ NMR $\left(500 \mathrm{MHz}, \mathrm{CDCl}_{3}\right): \delta 11.14(\mathrm{~s}, 2 \mathrm{H}$, CHO), 7.79 (s, 2H, Ar-H), 6.45 (br, s, 2H, -OH), 5.84 (br, s, $2 \mathrm{H},-\mathrm{OH}), 3.91\left(\mathrm{~m}, 2 \mathrm{H}, \mathrm{CH}\left(\mathrm{CH}_{3}\right)_{2}\right), 2.16\left(\mathrm{~s}, 6 \mathrm{H}, \mathrm{Ar}-\mathrm{CH}_{3}\right), 1.56$ $\left(\mathrm{d}, J=6.9 \mathrm{~Hz}, 12 \mathrm{H}, \mathrm{CH}\left(\mathrm{CH}_{3}\right)_{2}\right) \cdot{ }^{13} \mathrm{C} \mathrm{NMR}\left(125 \mathrm{MHz}, \mathrm{CDCl}_{3}\right)$ : 199.34, 156.21, 150.43, 143.55, 134.10, 133.71, 129.75, 118.18, $115.82,114.70,111.85,27.90,20.30,20.22$.

$R$-(-)-gossypol (6) were obtained by the same procedure in $85.5 \%$ yield; $95.2 \%$ ee by HPLC. $[\alpha]_{\mathrm{D}}^{20}=-341$ (c 0.160 , $\mathrm{MeOH}) .{ }^{1} \mathrm{H}$ NMR (500 MHz, $\mathrm{CDCl}_{3}$ ): 11.14 (s, 2H, CHO), 7.79 (s, 2H, Ar-H), 6.45 (br, s, 2H, -OH), 5.84 (br, s, 2H, $\mathrm{OH}), 3.91\left(\mathrm{~m}, 2 \mathrm{H}, \mathrm{CH}\left(\mathrm{CH}_{3}\right)_{2}\right), 2.16\left(\mathrm{~s}, 6 \mathrm{H}, \mathrm{Ar}-\mathrm{CH}_{3}\right), 1.56$ (d, $\left.J=6.9 \mathrm{~Hz}, 12 \mathrm{H}, \mathrm{CH}\left(\mathrm{CH}_{3}\right)_{2}\right) .{ }^{13} \mathrm{C} \mathrm{NMR}\left(125 \mathrm{MHz}, \mathrm{CDCl}_{3}\right): \delta$ 199.34, 156.21, 150.43, 143.55, 134.10, 133.71, 129.75, 118.18, 115.82, 114.70, 111.85, 27.90, 20.30, 20.22.

Synthesis of (-)-apogossypol (7) and (+)-apogossypol (8): A solution of sodium hydroxide $(17.2 \mathrm{~g}$ ) in distilled water $(30.8 \mathrm{~mL})$ in a two-neck flask was frozen in the refrigerator. The flask was then evacuated and flushed with argon using a balloon. The above prepared (-)-gossypol or (+)-gossypol (1.6 $\mathrm{g}, 3.08 \mathrm{mmol}$ ) was next added to the flask so carefully that it did not stick the wall. The reaction was then stirred at $90{ }^{\circ} \mathrm{C}$ for $1 \mathrm{~h}$ and cooled down and put in an ice bath. A solution of concentrated sulfuric acid $(17.6 \mathrm{~mL})$ in distilled water $(12.8$ $\mathrm{mL}$ ) was slowly dropped into via a syringe. The resulting precipitate was filtered, washed with distilled water to remove the salts and other impurity. The residue was dried in vacuum and stored in argon atmosphere. Compounds 7 (1.24 g, 86.6 $\%) ; 98.2 \%$ ee by HPLC. $[\alpha]_{\mathrm{D}}{ }^{20}=-93^{\circ}(\mathrm{c} 0.150, \mathrm{MeOH})$ and compound $8(1.21 \mathrm{~g}, 84.6 \%) ; 98.4 \%$ ee by HPLC. $[\alpha]_{\mathrm{D}}{ }^{20}=+$ $96^{\circ}$ (c $\left.0.160, \mathrm{MeOH}\right)$. Compounds 7 and 8 have the same ${ }^{1} \mathrm{H}$ NMR spectra (500 MHz, $\mathrm{CDCl}_{3}, \delta$ (ppm): 7.65 (s, 2H); 7.51 (s, 2H); 6.05 (s, 2H); 5.20 (s, 2H); $5.11(\mathrm{~s}, 2 \mathrm{H}) ; 3.86(\mathrm{~m}, 2 \mathrm{H})$; $2.19(\mathrm{~s}, 6 \mathrm{H}) ; 1.56(\mathrm{~d}, 12 \mathrm{H}, J=5.5 \mathrm{~Hz})$.

\section{RESULTS AND DISCUSSION}

Racemic gossypol (1) was obtained from cotton seeds collected in Vietnam according to the reported procedure [20]. As mentioned above, the resolution of ( \pm )-gosssypol has been reported. The most important report was about the use of commercially available amino acids to form diastereomeric adducts that could be separated by column chromatography or crystallization method due to distinctive differences in their $R_{f}$ values, followed by their hydrolysis in acid medium to give (-)-gossypol [19,21]. In order to resolve ( \pm )-gossypol, Jiang et al. [21] initially used commercially available chiral amino acids such as L-tryptophan, L-tyrosine and L-phenylalanine. 
However, the reaction gave a mixture of water soluble diastereomeric adducts leading to the inseparation by recrystallization or flash chromatography. The next reaction surveys were carried out using amino acid esters including L-tryptophan methyl ester, L-tyrosine methyl ester and L-phenylalanine methyl ester in several solvents including $\mathrm{CH}_{2} \mathrm{Cl}_{2}$, ethyl ether and methanol, respectively. It was concluded that methanol and L-tryptophan were the ideal choice for the resolution. Xoan et al. [22] have reported the resolution of (-)-gosssypol using L-phenylalanine methyl ester. However, the resolution yield was low and the procedure was unsatisfactory because both adducts were soluble in methanol.

Based on the literature reported regarding the resolution of ( \pm )-gossypol, we found the procedure reprorted by Jiang $e t$ al. [21] is most suitable for the resolution of ( \pm )-gossypol at larger scale since we need a big amount of (-)-gossypol for further modifications to obtain new derivatives while commercially available (-)-gossypol is very expensive. We used the procedure at the scale as reported. However, in the second step, the hydrolysis of the corresponding diastereoisomeric gossypol adduct by hydrochloric acid (37\%) in ether failed to give the desired (-)-gossypol. In this condition, TLC showed low yield and slow rate of the hydrolysis of corresponding diastereoisomeric gossypol adduct derived from L-tryptophan methyl ester (L-Trp-OMe). Additionally, the decomposition of the formed (-)-gossypol could be observed as a possible result of oxygen containing reaction atmosphere at reflux temperature. Next, the hydrolysis experiment was carried out under nitrogen atmosphere at the same scale. After $2 \mathrm{~h}$ of hydrolysis, low conversion to (-)-gossypol was shown by TLC. The decomposition of formed (-)-gossypol was still observed. It was possible that ambient temperature is not favourable for the hydrolysis and may be the reason for the decomposition. We examined the experiment under nitrogen atmosphere at ice-water temperature and found no decomposition, but low hydrolysis for $2 \mathrm{~h}$. In search for new chiral reagents for the resolution of racemic gossypol, we reasoned that D-tryptophan methyl ester may be an alternative choice for L-tryptophan methyl ester to resolve ( \pm )-gossypol. In fact, the reaction of D-tryptophan methyl ester hydrochloride in ethanol instead of methanol [17] with the racemic gossypol in the presence of equimolar $\mathrm{NaOH}$ at $45{ }^{\circ} \mathrm{C}$ gave diastereoisomeric gossypol adducts (Scheme-I). The reaction was almost completed in $2 \mathrm{~h}$. The $S g, R-(+)$-diastereoisomeric gossypol adduct (3) is precipitated and separated by filtration. In this step, (+)-diastereoisomeric gossypol adduct (3) derived from D-tryptophan methyl ester was found to crystallize out first from the reaction in quantitative yield. The chemical and optical purity were determined to be up to 98.5 and $99 \%$, respectively by analysis on HPLC using reported procedure [23] with optical rotation $\left\{[\alpha]_{\mathrm{D}}{ }^{20}=+222\right.$ (c $\left.0.160, \mathrm{CHCl}_{3}\right\}$. The mother liquor was then extracted with water and dichloromethane to remove inorganic substances. The organic phase was then concentrated to obtain the (-)-diastereoisomeric gossypol adduct which was recrystallized in methylene chloride to give the $R \mathrm{~g}, R$-(-)-diastereoisomeric gossypol adduct (4) with chemical and optical high purity in 98.7 and $99 \%$, respectively, with optical rotation $\left\{[\alpha]_{\mathrm{D}}{ }^{20}=-106\left(\mathrm{c} 0.160, \mathrm{CHCl}_{3}\right\}\right.$.

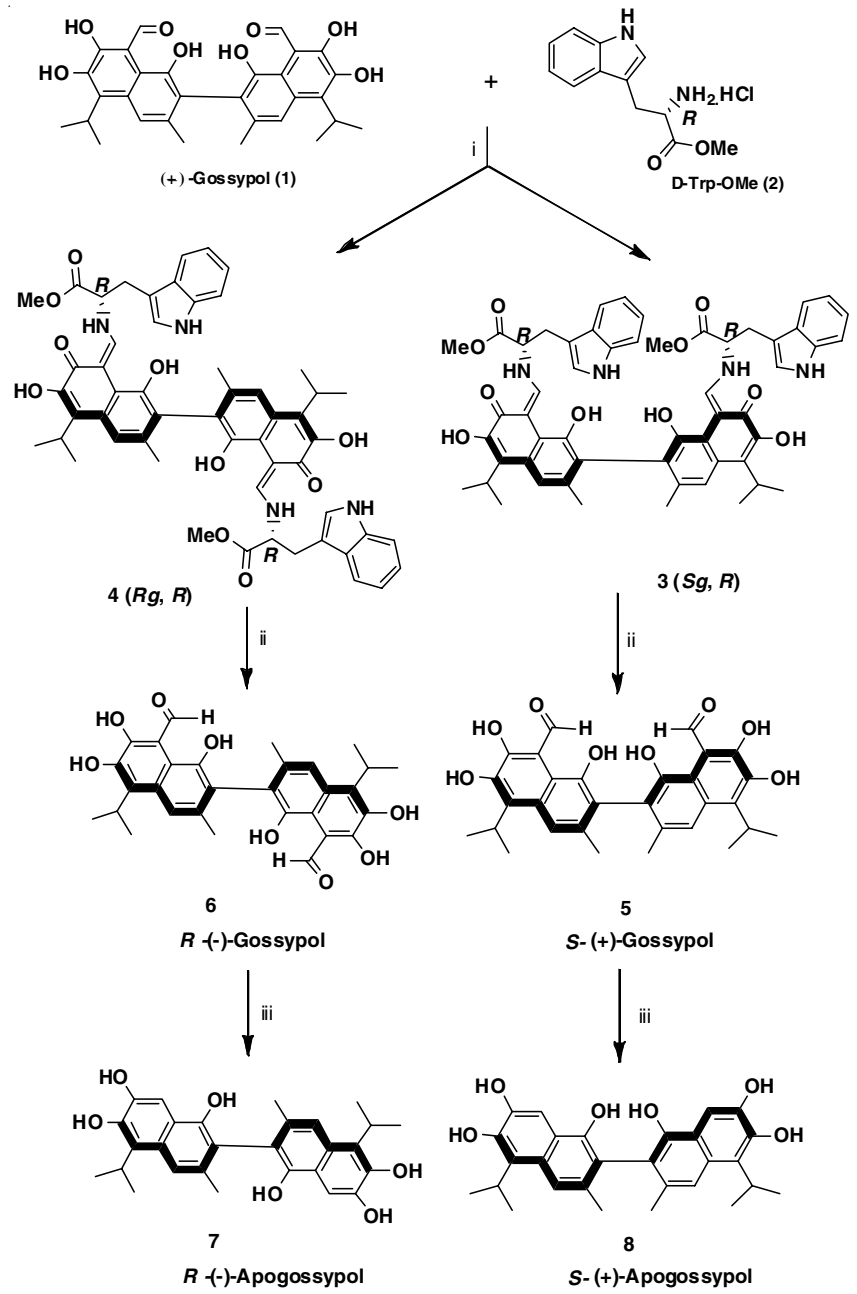

Scheme-I: Resolution of ( \pm )-gossypol by D-tryptophan methyl ester. $\mathrm{HCl}$ : (i) $\mathrm{NaOH}, \mathrm{EtOH}, 45^{\circ} \mathrm{C}, 2 \mathrm{~h}$; (ii) acetic acid:ether (4:1), $\mathrm{HCl}$ ( $37 \%), 0{ }^{\circ} \mathrm{C}$-room temperature, $72 \mathrm{~h}(85 \%)$; (iii) $\mathrm{NaOH} 40 \%$, $1 \mathrm{~h} ; \mathrm{H}_{2} \mathrm{SO}_{4}(84-86.6 \%)$

The hydrolytic step to liberate the resolved gossypol from the diastereoisomerically pure adducts $(\mathbf{3})$ and $(\mathbf{4})$ were conducted in the mixture of acetic acid and ether under inert atmosphere. Different ratios of acetic acid and ether were examined. In our experiment, the ratio of acetic acid and ether (4:1) was found to be the most suitable for the hydrolysis. After $72 \mathrm{~h}$ of hydrolysis under nitrogen atmosphere, $S$-(+)gossypol (5) and $R$-(-)-gossypol (6) were obtained by crystallization procedure in the mixture of dichloromethane and $n$ hexane. It was also found in this experiment that the ratio $(2: 1)$ of dichloromethane and $n$-hexane was most suitable for crystallization to afford high yields of enantiomers.

Apogossypol is formed by the base catalyzed deformylation of gossypol. Apoggsypol was firstly prepared by Clark [24] using $\mathrm{NaOH}$ as a deformylation agent of gossypol at the temperature of steam bath in open atmosphere. In this condition, gossypol was converted to formic acid and apogossypol with the ratio 2:1. Due to oxidative instability of apogossypol, Powers and Dorsett [25] modified the procedure to prepare apogossypol from racemic gossypol in an inert atmosphere to obtain apogossypol with improved yields. The key point of this procedure was the base catalyzed deformylation of gossypol conducted in inert atmosphere and elevated tempe- 
rature, leading to the improved yield. However, the reaction scale was small and apogossypols obtained were in the racemic forms. In this report, (-)-apogossypol or (+)-apogossypol were prepared from the corresponding (-)-gossypol and (+)gossypol in high yields and enantiomeric purity via a simple and modified procedure. The deformylation reaction of the corresponding (-)-gossypol and (+)-gossypol was performed in $40 \% \mathrm{NaOH}$ solution at $90{ }^{\circ} \mathrm{C}$ for $1 \mathrm{~h}$, followed by $\mathrm{H}_{2} \mathrm{SO}_{4}$ neutralization in inert atmosphere. The resulting precipitate was carefully washed with distilled water and dried in vacuum to give the corresponding (-)-apogossypol and (+)-apogossypol in high yields. The HPLC analysis showed the enantiomeric purity of (-)-apogossypol (7) and (+)-apogossypol (8) corresponding to 98.2 and $98.4 \%$, respectively.

\section{Conclusion}

To our best of knowledge, it is the first time D-tryptophan methyl ester has been used for effectively resolution of racemic gossypol into (-)-gossypol and (+)-gossypol via a facile twostep procedure in high enantiomeric excess and yields. These enantiomers have been then converted to the corresponding (-)-apogossypol and (+)-apogossypol in high enantiomeric and yields. This procedure could also be potential for scaling up to prepare optically gossypol and apogossypol for different purposes, especially in the pharmaceutical field.

\section{ACKNOWLEDGEMENTS}

The authors thank Vietnam Ministry of Science and Technology for financial support via a project: NĐT.08.GER.15.

\section{CONFLICT OF INTEREST}

The authors declare that there is no conflict of interests regarding the publication of this article.

\section{REFERENCES}

1. C.L. Oliver, J.A. Bauer, K.G. Wolter, M.L. Ubell, A. Narayan, K.M. O'Connell, S.G. Fisher, S. Wang, X. Wu, M. Ji, T.E. Carey and C.R. Bradford, Clin. Cancer Res., 10, 7757 (2004);

https://doi.org/10.1158/1078-0432.CCR-04-0551.

2. M. Zhang, H. Liu, Z. Tian, B.N. Griffith, M. Ji and Q.Q. Li, Life Sci, 80, 767 (2007); https://doi.org/10.1016/j.lfs.2006.11.004.

3. R.M. Mohammad, S. Wang, S. Banerjee, X. Wu, J. Chen and F.H. Sarkar, Pancreas, 31, 317 (2005); https://doi.org/10.1097/01.mpa.0000179731.46210.01.

4. M. Zhang, H. Liu, R. Guo, Y. Ling, X. Wu, B. Li, P.P. Roller, S. Wang and D. Yang, Biochem. Pharmacol., 66, 93 (2003); https://doi.org/10.1016/S0006-2952(03)00248-X.

5. D.W. Hahn, C. Rusticus, A. Probst, R. Homm and A.N. Johnson, Contraception, 24, 97 (1981); https://doi.org/10.1016/0010-7824(81)90072-X.
6. J. Yang, G. Chen, L.L. Li, W. Pan, F. Zhang, J. Yang, S. Wu and P. Tien, Bioorg. Med. Chem. Lett., 23, 2619 (2013); https://doi.org/10.1016/j.bmcl.2013.02.101.

7. J. Yang, F. Zhang, J.R. Li, G. Chen, S.W. Wu, W.J. Ouyang, W. Pan, R. Yu, J.X. Yang and P. Tien, Bioorg. Med. Chem. Lett., 22, 1415 (2012); https://doi.org/10.1016/j.bmcl.2011.12.076.

8. R.J. Radloff, L.M. Deck, R.E. Royer and D.L. Vander Jagt, Pharmacol. Res. Commun., 18, 1063 (1986); https://doi.org/10.1016/0031-6989(86)90023-8.

9. G. Tegos, F.R. Stermitz, O. Lomovskaya and K. Lewis, Antimicrob. Agents Chemother, 46, 3133 (2002); https://doi.org/10.1128/AAC.46.10.3133-3141.2002.

10. J. Qiu, L.K. Levin, J. Buck and M.M. Reidenberg, Exp. Biol. Med., 227, 398 (2002); https://doi.org/10.1177/153537020222700605.

11. G. Tang, C.-Y. Yang, Z. Nikolovska-Coleska, J. Guo, S. Qiu, R. Wang, W. Gao, G. Wang, J. Stuckey, K. Krajewski, S. Jiang, P.P. Roller and S. Wang, J. Med. Chem. Lett., 50, 1723 (2007); https://doi.org/10.1021/jm0614001.

12. X.S. Liang, A.J. Rogers, C.L. Webber, T.J. Ormsby, M.E. Tiritan, S.A. Matlin and C.C. Benz, Invest. New Drugs, 13, 181 (1995); https://doi.org/10.1007/BF00873798.

13. S. Kitada, C.L. Kress, M. Krajewska, L. Jia, M. Pellecchia and J.C. Reed, Blood, 111, 3211 (2008); https://doi.org/10.1182/blood-2007-09-113647.

14. L. Coward, G. Gorman, P. Noker, C. Kerstner-Wood, M. Pellecchia, J.C. Reed and L. Jia, J. Pharm. Biomed. Anal., 42, 581 (2006); https://doi.org/10.1016/j.jpba.2006.05.020.

15. J. Wei, J.L. Stebbins, S. Kitada, R. Dash, W. Placzek, M.F. Rega, B. Wu, J. Cellitti, D. Zhai, L. Yang, R. Dahl, P.F. Fisher, J.C. Reed and M. Pellecchia, J. Med. Chem., 53, 4166 (2010); https://doi.org/10.1021/jm1001265.

16. J. Wei, S. Kitada, M.F. Rega, J.L. Stebbins, D. Zhai, J. Cellitti, H. Yuan, A. Emdadi, R. Dahl, Z. Zhang, L. Yang, J.C. Reed and M. Pellecchia, J. Med. Chem., 52, 4511 (2009); https://doi.org/10.1021/jm900472s.

17. J. Wei, M.F. Rega, S. Kitada, H. Yuan, D. Zhai, P. Risbood, H.H. Seltzman, C.E. Twine, J.C. Reed and M. Pellecchia, Cancer Lett., 273, 107 (2009); https://doi.org/10.1016/j.canlet.2008.07.031.

18. J. Wei, S. Kitada, M.F. Rega, A. Emdadi, H. Yuan, J. Cellitti, J.L. Stebbins, D. Zhai, J. Sun, L. Yang, R. Dahl, Z. Zhang, B. Wu, S. Wang, T.A. Reed, N. Lawrence, A. Sebti, J.C. Reed and M. Pellecchia, Mol. Cancer Ther, 8, 904 (2009); https://doi.org/10.1158/1535-7163.MCT-08-1050.

19. A.I. Meyers and J.J. Willemsen, Chem. Commun., 16, 1573 (1997); https://doi.org/10.1039/a703043f.

20. R. Chandrashekar, A.K. Kumar, Y.R. Reddy and P.J. Chaitanyal, J. Pharmacogn. Phytochem., 2, 180 (2013).

21. H.X. Jiang, X.X. Cao, H. Huang and B. Jiang, Tetrahedron Asymm., 18, 2437 (2007); https://doi.org/10.1016/j.tetasy.2007.09.032.

22. L.T. Xoan, N.T.T. Trang, N.T. Ha, N.V. Quang and N.V. Tai, J. Med. Mater, 15, 149 (2010) (in Vietnamese).

23. S.A. Matlin, A. Belenguer, R.G. Tyson and A.N. Brookes, J. High Resolut. Chromatogr. Chromatogr. Commun., 10, 86 (1987); https://doi.org/10.1002/jhrc.1240100207.

24. E.P. Clark, J. Biol. Chem., 58, 159 (1928).

25. L.J. Powers and P.H. Dorsett, J. Label. Comp. Radiopharm., 17, 309 (1980); https://doi.org/10.1002/jlcr.2580170219. 